\title{
Dimethyloxalylglycine Promotes Bone Marrow Mesenchymal Stem Cell Osteogenesis via Rho/ROCK Signaling
}

\author{
Lei Zhang ${ }^{\text {a }}$ Guoliang Jiang $^{b}$ Xueling Zhaoc ${ }^{\text {Yuekun Gong }}$
}

\begin{abstract}
aDepartment of rehabilitation medicine, the first people's hospital of Yunnan province, Kunming, bDepartment of neurosurgery, the first affiliated hospital of Kunming medical university, Kunming, 'Department of orthopaedics, the first affiliated hospital of Kunming medical university, Kunming, China
\end{abstract}

\section{Key Words}

Dimethyloxalylglycine $\bullet$ Bone marrow mesenchymal stem cells $\bullet$ ROCK $\bullet$ RhoA $\bullet$ Osteogenesis

\begin{abstract}
Background/Aims: We investigated the role of dimethyloxalylglycine (DMOG) in bone marrow mesenchymal stem cell (BMSC) osteogenesis mediated by RhoA/ROCK. Methods: BMSCs were cultured with and without DMOG and/or Y-27632 (ROCK1 inhibitor). Cell proliferation, alkaline phosphatase (ALP) levels, and calcium deposits were determined. The expression of Runx2, OSX, p-cofilin, RhoA, and GTP-bound RhoA was determined by real-time RT-PCR and Western blot. Rho-associated coiled-coil-containing protein kinase (ROCK) activity was determined by measuring the phosphorylation of myosin-binding subunit of myosin phosphatase using an ELISA kit. Actin morphology was observed by immunofluorescence. Results: After 24 h, DMOG (0.5 mM) increased the expression of GTP-bound RhoA $(+141 \%, P<0.001)$ and enhanced ROCK activity $(315 \%, P<0.001)$. DMOG $(0.5 \mathrm{mM})$ enhanced ALP levels after 3,7 , and 21 days of osteogenic induction (all $P<0.001$ ) and strengthened calcium deposition $(P<0.001)$. In addition, compared with controls, DMOG $(0.5 \mathrm{mM})$ increased the mRNA levels of osteogenesis genes $R U N X 2$ and OSX (all $P<0.001$ ). Furthermore, compared with controls, DMOG increased the expression of $p$-cofilin $(+57 \%, P<0.001)$, which resulted in rearrangement of actin filaments. All these effects were abolished, at least in part, by Y-27632. Conclusion: DMOG promotes BMSC osteogenic differentiation via activation of RhoA/ROCK, suggesting clues for future therapies using BMSCs.

(C) 2016 The Author(s)

Published by S. Karger AG, Basel
\end{abstract}

\section{Introduction}

Dimethyloxalylglycine (DMOG) is a prolyl hydroxylase inhibitor (PHI), which is a rate-limiting enzyme in the degradation of hypoxia inducible factor (HIF) [1]. Therefore, DMOG physiologically 


\section{Cellular Physiology Cell Physiol Biochem 2016;39:1391-1403

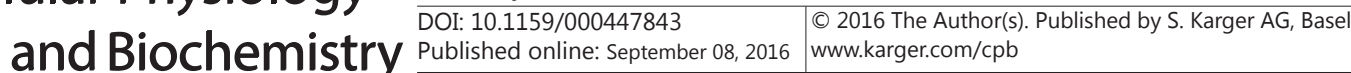 \\ Zhang et al.: Dimethyloxalylglycine Promotes BMSC Osteogenesis}

simulates low oxygen environment by blocking the degradation of HIF, and inducing chemical hypoxia [2, 3]. Approximately 100 downstream target genes of HIF are involved in cellular energy metabolism, ion metabolism, angiogenesis, cell differentiation, apoptosis, cellular proliferation, and migration $[4,5]$. Zhou et al. reported that HIF-1 $\alpha$ inhibited BMP2-induced stem cell osteogenesis [6]. Recent studies suggest that DMOG plays an important role in osteogenic differentiation, which is debatable. Indeed, Irwin et al. [7] showed that DMOG increased adipogenic gene expression and decreased osteoblastic genes. On the other hand, Woo et al. [8]reported that DMOG accelerated bone regeneration, which is supported by Peng et al. [9] showing that DMOG prevented bone loss after ovariectomy.

Previous studies demonstrated that RhoA/ROCK signaling pathway plays a key role in cellular processes including smooth muscle contraction, stress fiber formation, cell migration, cell division, cell adhesion, and cell differentiation by regulating the actin cytoskeleton [10-15]. Previous studies showed that the RhoA/ROCK signaling pathway regulated osteogenesis. Indeed, Wang et al. [16] reported that bone morphogenic protein (BMP) promotes human mesenchymal stem cell (MSC) osteogenesis by altering cytoskeleton via activation of RhoA/ROCK signaling. Other studies showed that osteogenic growth peptide (OGP) [17], connective tissue growth factor [18], extracellular matrix [19], and hydrostatic pressure [20] promote the osteogenic differentiation of human bone marrow MSC (BMSC) via RhoA/ROCK signaling activation.

In RhoA/ROCK signaling, GTP-bound RhoA activates Rho-associated coiled-coil-containing protein kinase (ROCK1), which phosphorylates the threonine of LIM kinase 1 (LIMK1) at positions 505 and 508. The phosphorylated LIMK inactivates cofilin by phosphorylating the serine of cofilin at position 3 . Cofilin modulates actin rearrangement by truncating actin filaments and depolymerizing F-actin. However, phosphorylated cofilin (p-cofilin) has no effect on F-actin [21-25].

Until now, the precise mechanism of DMOG in the regulation of MSC osteogenesis remains unclear. Understanding the specific cellular signaling pathways mediating DMOG-induced osteogenesis is an important step toward the regulation of MSC osteogenic differentiation and their clinical application. Vogel et al. [26]found that DMOG treatment of Hela cells or prolyl hydroxylase domain (PHD)-knockout HeLa cells activated RhoA/ROCK signaling independent of HIF by inhibiting PHD. The activation of RhoA/ROCK alters the cytoskeleton and cell migration.

Therefore, the aim of this study was to investigate the role of DMOG in BMSC osteogenesis and determine whether the altered cell shape following the activation of RhoA/ROCK signaling induced osteogenic differentiation of DMOG-induced MSCs.

\section{Materials and Methods}

Isolation, culture, and identification of BMSCS

Three-week-old male Kunming mice ( $\mathrm{n}=20)$ weighing 18-20g were purchased from the experimental animal center of Kunming Medical University (Yunnan, China). BMSCs were isolated and cultured as previously described [27]. Briefly, mice bone marrow was collected by flushing the cavities of femurs and tibias with DMEM (GIBCO, Invitrogen Inc., Carlsbad, CA, USA). Whole bone marrow cells were seeded in $1 \times 10^{6}$ in culture flasks supplemented with DMEM and $10 \%$ fetal bovine serum (FBS) (Hyclone, Thermo Fisher Scientific, Waltham, MA, USA). The flasks were incubated with $5 \% \mathrm{CO}_{2}$ at $37^{\circ} \mathrm{C}$. After $48 \mathrm{~h}$, nonadherent cells were washed out. When the cells reached approximately $80 \%$ confluence, the cells were subcultured at 1:2 or 1:3. BMSCs were used after four to six passages.

Anti-CD90-FITC (Beckman-Coulter, Brea, CA, USA), anti-CD44-FITC (Beckman-Coulter), anti-CD105PE (Beckman-Coulter), and anti-CD34-PC5 (Beckman-Coulter) antibodies were used for flow cytometry (EPICS-XL, Beckman Coulter). CD44+ CD90+ CD105+ CD34- cells were identified as BMSCs (CD90: 98.5\%; CD105: 99.9\%; CD44: 99.0\%; CD34: 0.1\%) (Fig. 1).

BMSCs differentiated into osteoblasts using an osteogenic medium (10\% FBS, low glucose DMEM, 50 $\mu \mathrm{g} / \mathrm{mL}$ of vitamin C, $10 \mathrm{mmol} / \mathrm{L}$ of $\beta$-glycerophosphate, and $10^{-8} \mathrm{~mol} / \mathrm{L}$ of dexamethasone) [28]for 14 days. Calcium deposition was evaluated using an alizarin red solution (Fig. 2A). 


\section{Cellular Physiology Cell Physiol Biochem 2016;39:1391-1403 \begin{tabular}{ll|l} 
and Biochemistry $10.1159 / 000447843$ & $\begin{array}{l}\text { O } 2016 \text { The Author(s). Published by S. Karger AG, Basel } \\
\text { wwww.karger.com/cpb }\end{array}$
\end{tabular}

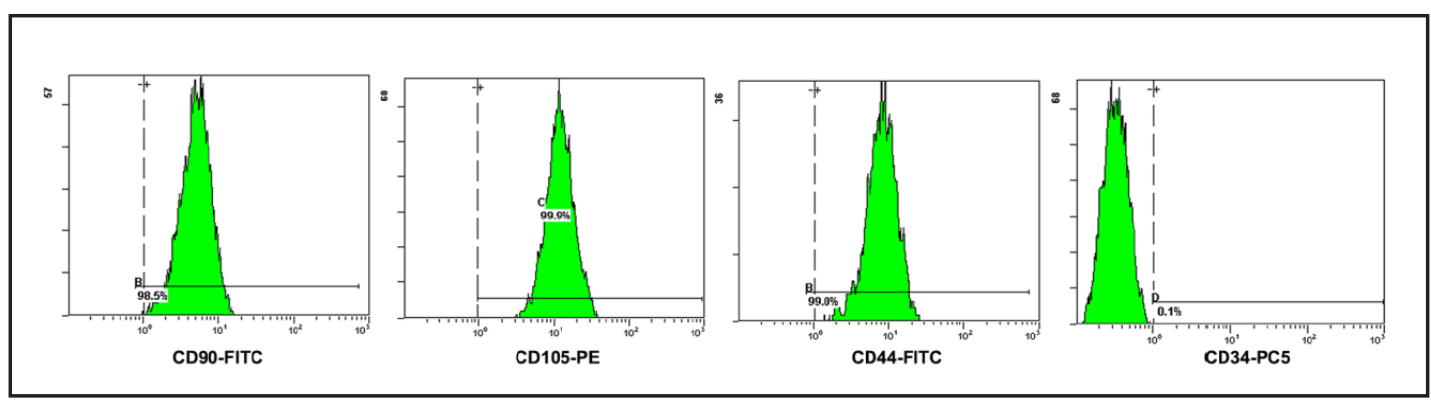

Fig. 1. Phenotypes of BMSCs detected by flow cytometry.

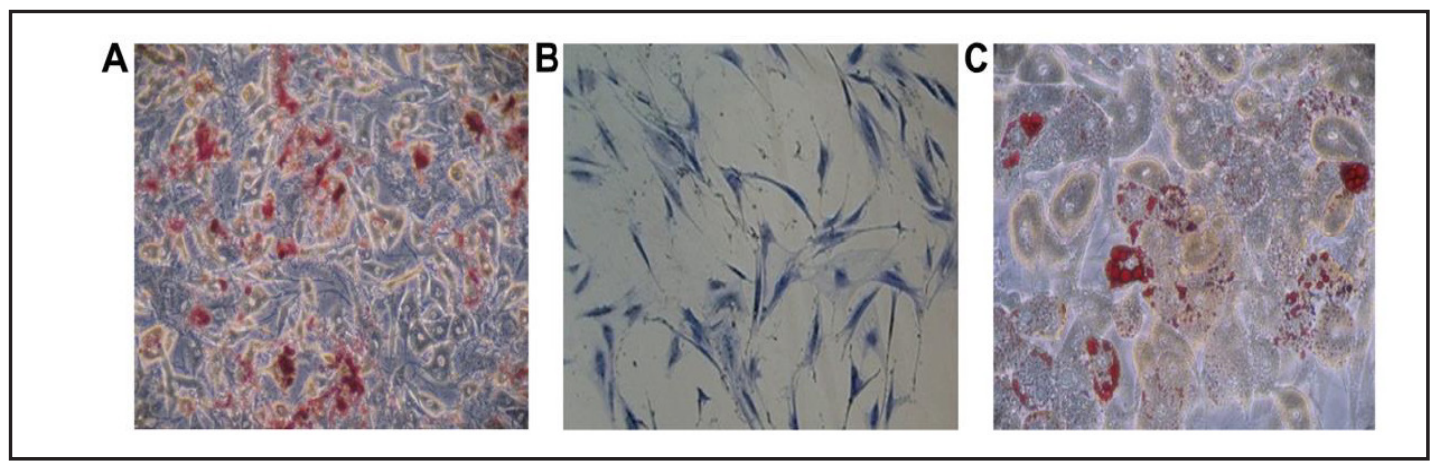

Fig. 2. Osteogenic, chondrogenic and adipogenic differentiation of BMSCs at passage 4 (magnification: $\times 200$ ). (A) Osteogenic differentiation of BMSCs (Alizarin red stain). (B) Chondrogenic differentiation (toluidine blue staining). (C) Adipogenic differentiation of BMSCs (oil red 0 stain).

BMSCs also differentiated into chondrocytes using a chondrogenic medium (10\% FBS, low glucose DMEM, $5 \times 10^{-4} \mathrm{~mol} / \mathrm{L}$ of IBMX, $2 \times 10^{-4} \mathrm{~mol} / \mathrm{L}$ of indomethacin, $10 \mu \mathrm{g} / \mathrm{mL}$ of insulin, $10^{-7} \mathrm{~mol} / \mathrm{L}$ of dexamethasone, $6.25 \mathrm{mg} / \mathrm{mL}$ of transferrin, and $50 \mu \mathrm{g} / \mathrm{mL}$ of vitamin C) [29] for 14 days. Differentiation was evaluated by toluidine blue staining (Fig. 2B).

BMSCs also differentiated into adipocytes using an adipogenic medium (10\% FBS, high glucose DMEM, $5 \times 10^{-4} \mathrm{~mol} / \mathrm{L}$ of IBMX, $2 \times 10^{-4} \mathrm{~mol} / \mathrm{L}$ of indomethacin, $10 \mu \mathrm{g} / \mathrm{ml}$ of insulin, and $10^{-6} \mathrm{~mol} / \mathrm{L}$ of dexamethasone) [30] for 7 days. Lipid vesicles were identified by oil-red 0 staining (Fig. 2C).

All the experiments were approved by the Animal Ethics Committee of Kunming Medical University. All efforts were made to minimize animal suffering and minimize the number of animals used.

\section{Cell proliferation}

Cell proliferation was estimated using the 3-(4,5-dimethylthiazol-2-yl)-2,5-diphenyltetrazolium bromide (MTT) assay. BMSCs at passage 5 were seeded on 96 -well plates at $1 \times 10^{4} / \mathrm{mL}(200 \mu \mathrm{L} /$ well) in low-glucose DMEM and 10\% FBS. They were treated with different concentrations $(0,0.1,0.5,1$, and 2 mM) of DMOG (Cayman Chemical, Ann Arbor, MN, USA) for 24, 48, 72, and 96 h. After DMOG treatment, the cell culture medium was discarded and the cells were treated with $150 \mu \mathrm{L}$ of MTT (5 mg/mL; Invitrogen Inc., Carlsbad, CA, USA) for $4 \mathrm{~h}$. After careful removal of culture media, $150 \mu \mathrm{L}$ of DMSO were added to fully dissolve the purple crystals by shaking for $10 \mathrm{~min}$. The absorbance in each well was measured at $490 \mathrm{~nm}$ using Model 550 automatic microplate reader (Bio-Rad, Hercules, CA, USA).

\section{Alkaline phosphatase levels}

Alkaline phosphatase (ALP) levels were determined by colorimetry using an ALP assay kit (Jiancheng Bioengineering institute, Nanjing, China). BMSCs were seeded on 6-well plates at a density of $1 \times 10^{5}$ cells/ well, and treated with different concentrations $(0,0.1,0.5,1$, and $2 \mathrm{mM})$ of DMOG in osteogenic medium for 3, 7, 14, and 21 days, osteogenic medium (control), osteogenic medium containing $0.5 \mathrm{mM}$ of DMOG, osteogenic medium containing $10 \mu \mathrm{M}$ of Y-27632 (ROCK inhibitor; Cayman Chemical, Ann Arbor, MN, 


\section{Cellular Physiology Cell Physiol Biochem 2016;39:1391-1403 and Biochemistry \begin{tabular}{l|l} 
DOI: $10.1159 / 000447843$ & (c) 2016 The Author(s). Published by S. Karger AG, Basel \\
www.karger.com/cpb
\end{tabular} \\ Zhang et al.: Dimethyloxalylglycine Promotes BMSC Osteogenesis}

USA), and osteogenic medium containing $0.5 \mathrm{mM}$ of DMOG and $10 \mu \mathrm{M}$ of Y-27632 for 3, 7, 14, and 21 days. After treatment, cells were lysed with RIPA buffer (Invitrogen Inc., Carlsbad, CA, USA) at $37^{\circ} \mathrm{C}$ for 15 min, and treated with the chromogenic agent provided by the kit. According to previous studies and our preexperiments, $10 \mu \mathrm{M}$ of Y-27632 was used to inhibit the activity of ROCK in our experiment [31]. A standard phenol solution replaced the cell lysis solution. The blank tube contained double-distilled water instead of cell lysis solution. The blank tube was used to adjust "zero". The absorbance in each tube was measured at $520 \mathrm{~nm}$. ALP levels were determined as follows: $\mathrm{ALP}=(\mathrm{KingU} / 100 \mathrm{~mL})=\left(\mathrm{OD}\right.$ test tube $\left./ O D_{\text {Standard tube }}\right) \times 0.005$ $\mathrm{mg} \times(100 \mathrm{~mL} / 0.05 \mathrm{~mL})$.

\section{Real-time RT-PCR}

BMSCs were treated with osteogenic medium (control), osteogenic medium containing $0.5 \mathrm{mM}$ of DMOG, osteogenic medium containing $10 \mu \mathrm{M}$ of Y-27632, or osteogenic medium containing $0.5 \mathrm{mM}$ of DMOG and $10 \mu \mathrm{M}$ of Y-27632 for 1, 3, and 7 days. BMSCs were harvested and the total RNA was isolated using TRIzol (Invitrogen Inc., Carlsbad, CA, USA). The 260/280 nm absorbance ratio was used to determine the purity and concentration of the RNA. The cDNA was synthesized using a SuperScript ${ }^{\mathrm{TM}}$ III First-Strand Synthesis System for RT-PCR (Invitrogen Inc., Carlsbad, CA, USA). The primer sequences were: Runx2, forward 5'-TTC AAC GAT CTG AGA TTT GTG GG-3' and reverse 5'-GGA TGA GGA ATG CGC CCT A-3'; Osterix, forward 5'-ATG GCG TCC TCT CTG CTT G-3' and reverse 5'-TGA AAG GTC AGC GTA TGG CTT-3'; and $\beta$-actin, forward 5'-GTG ACG TTG ACA TCC GTA AAG A-3' and reverse 5'-GCC GGA CTC ATC GTA CTC C-3'. Analysis was performed using an ABI prism 7000 real-time PCR system (Applied Biosystems, Foster City, CA, USA) and Platinum SYBR Green qPCR (Invitrogen Inc., Carlsbad, CA, USA). All reactions involved initial denaturation at $95^{\circ} \mathrm{C}$ for $2 \mathrm{~min}$ followed by 40 cycles of $95^{\circ} \mathrm{C}$ for $15 \mathrm{~s}, 54^{\circ} \mathrm{C}$ for $30 \mathrm{~s}$, and $65^{\circ} \mathrm{C}$ for $20 \mathrm{~s}$. The $2^{-\Delta \Delta \mathrm{Ct}} \operatorname{method}$ was used to represent the relative mRNA expression of target genes. $\beta$-actin was used as an internal control.

\section{Western blot}

BMSCs were treated with osteogenic medium (control), osteogenic medium containing $0.5 \mathrm{mM}$ of DMOG, osteogenic medium containing $10 \mu \mathrm{M}$ of Y-27632, or osteogenic medium containing $0.5 \mathrm{mM}$ of DMOG and $10 \mu \mathrm{M}$ of Y-27632 for 24h. BMSCs were harvested and lysed using RIPA buffer (Beyotime Biotechnology, Jiangsu, China). Protein levels in the supernatant were determined using the BCA Protein Assay Kit (Tiangen Biotech (Beijing) Co., Ltd., Beijing, China). Equal amounts of proteins (20 $\mu$ g) were separated on 6-18\% SDS-PAGE and transferred to PVDF membranes (Millipore corp., Billerica, MA, USA). The membranes were blocked with $5 \%$ skim milk for $1 \mathrm{~h}$, and washed with TBST three times. The membranes were incubated with a primary antibody against p-cofilin (\#3313; 1:1000; Cell Signaling, Danvers, MA, USA), RhoA(\#05778;1:1000; Millipore corp., Billerica, MA, USA ),GAPDH (\#5174; 1:1000; Cell Signaling, Danvers, MA, USA), overnight at $4^{\circ} \mathrm{C}$. The membranes were incubated with HRP-conjugated secondary antibodies for $1 \mathrm{~h}$ at room temperature. Protein expression signals were visualized by ECL (Beyotime Biotechnology, Jiangsu, China). Band intensity was quantified using the Image J software (National Institutes of Health, Bethesda, MD, USA).

\section{RhoA activation assay}

BMSCs were treated with osteogenic medium (control), osteogenic medium containing $0.5 \mathrm{mM}$ of DMOG, osteogenic medium containing $10 \mu \mathrm{M}$ of Y-27632, or osteogenic medium containing $0.5 \mathrm{mM}$ of DMOG and $10 \mu \mathrm{M}$ of Y-27632.Cells were harvested on day 1 and lysed with lysis buffer (Invitrogen Inc., Carlsbad, CA, USA). Twenty microliters of supernatant was used to determine the expression of total RhoA. The remaining supernatant was used to isolate GTP-bound RhoA using the Rho activation assay kit (Millipore corp., Billerica, MA, USA) according to the manufacturer's instructions. Briefly, supernatants were incubated with rhotekin-binding domain beads and glutathione S-transferase-Rho-binding domain of mouse rhotekin contained in the Rho Assay Reagent was combined with GTP-Rho. Later, the GTP-Rho was isolated.The GTPbound RhoA and RhoA were detected by Western blot using a monoclonal antibody to RhoA. The membranes were incubated with HRP-conjugated secondary antibodies for $1 \mathrm{~h}$ at room temperature. Protein expression signals were visualized by ECL (Beyotime Biotechnology, Jiangsu, China). Band intensity was quantified using the Image J software (National Institutes of Health, Bethesda, MD, USA).

\section{KARGER}




\section{Cellular Physiology Cell Physiol Biochem 2016;39:1391-1403 \begin{tabular}{l|l|l|l|l}
\hline DOI: 10.1159/000447843 & (c) 2016 The Author(s). Published by S. Karger AG, Basel \\
www.karger.com/cpb
\end{tabular} \\ Zhang et al.: Dimethyloxalylglycine Promotes BMSC Osteogenesis}

ROCK activity assay

BMSCs were treated with osteogenic medium (control), osteogenic media containing $0.5 \mathrm{mM}$ of DMOG, $10 \mu \mathrm{M}$ of Y-27632, or $0.5 \mathrm{mM}$ of DMOG and $10 \mu \mathrm{M}$ of Y-27632 for $24 \mathrm{~h}$. BMSCs were harvested and re-suspended with cell extraction buffer (Invitrogen Inc., Carlsbad, CA, USA). The re-suspended cells were lysed using three cycles of freezing and thawing. Cell lysates were centrifuged at $12000 \mathrm{~g}$ for $10 \mathrm{~min}$. Supernatants were obtained and the ROCK activity was measured using a Rho-kinase Assay Kit (Cyclex Co., Ltd, Nagano, Japan) according to the manufacturer's instructions. ROCK activity was expressed as milliunits per microgram of protein with Cyclex ROCK positive control as a reference.

\section{Calcium deposition assay}

Calcium deposition was qualitatively detected by alizarin red staining. Briefly, BMSCs were seeded at a density of $5 \times 10^{4}$ cells per well in 24-well plates, treated with osteogenic medium (control), osteogenic media containing $0.5 \mathrm{mM}$ of DMOG, $10 \mu \mathrm{M}$ of Y-27632, or $0.5 \mathrm{mM}$ of DMOG and $10 \mu \mathrm{M}$ of Y-27632, and cultured for 21 days. Cells were fixed in $4 \%$ formaldehyde for $30 \mathrm{~min}$. After washing with PBS three times, the cells were incubated in $0.1 \%$ alizarin red solution (Aladdin Chemicals Co., Ltd., Shanghai, China) for 10 min. Staining intensity was observed under an IX71 Inverted microscope (Olympus, Tokyo, Japan)

Calcium deposition was quantitatively detected by colorimetry using a calcium assay kit (Jiancheng Bioengineering institute, Nanjing, China). Briefly, the cells were rinsed with PBS and exposed to $0.5 \mathrm{~mol} / \mathrm{L}$ hydrochloric acid $(\mathrm{HCl})$ overnight. The cells were harvested and centrifuged at $12000 \mathrm{~g}$ for 10 min. The supernatants were quantified spectrophotometrically at $610 \mathrm{~nm}$ by reacting with methylthymol blue complexone. Calcium concentration was calculated from the standard curve of serial dilutions of a calcium standard solution, and the values were normalized to DNA content (expressed in mg calcium/mg DNA). DNA assay was performed using FluoReporter Blue Fluorometric dsDNA Quantitation Kit (Molecular Probes,OR, USA) according to the manufacturer's instructions.

\section{Immunofluorescence staining}

BMSCs were seeded at a density of $5 \times 10^{4}$ cells per well in 6-well plates with osteogenic medium. After the cells were adherent, BMSCs were treated with osteogenic medium (control), osteogenic media containing $0.5 \mathrm{mM}$ of DMOG, $10 \mu \mathrm{M}$ of Y-27632, or $0.5 \mathrm{mM}$ of DMOG and $10 \mu \mathrm{M}$ of Y-27632 for $24 \mathrm{~h}$. After treatment, cells were fixed with $4 \%$ paraformaldehyde for $30 \mathrm{~min}$. Cells were washed with PBS and incubated with $0.1 \%$ Triton X-100 for 5 min. After washing, nonspecific binding was blocked by incubation with blocking solution (1\% BSA in PBS) for 30 min. Cells were incubated with $5 \mu \mathrm{g} / \mathrm{mL}$ of FITC-labeled phalloidin (ENZO) overnight at $4^{\circ} \mathrm{C}$ in the dark. Cells were analyzed by 90 I fluorescence microscopy (NIKON, Tokyo, Japan).

\section{Statistical Analysis}

The data was analyzed with SPSS 17.0 (IBM, Armonk, NY, USA). All the data are shown as mean \pm standard deviation. Statistical significance was evaluated by one-way analysis of variance (ANOVA) with the Student-Newman-Keuls (SNK) test for post hoc analysis. Two-sided $P$-values $<0.05$ were considered statistically significant.

\section{Results}

DMOG inhibited BMSC proliferation and promoted ALP levels during BMSC osteogenic differentiation

To determine the effect of DMOG on the proliferation of BMSCs, a MTT assay was performed. After $24 \mathrm{~h}$ and compared with the control group, $1 \mathrm{mM}(-2.21 \% ; P<0.05)$ and $2 \mathrm{mM}(-6.12 \%$; $P<0.05)$ of DMOG inhibited BMSCs proliferation. BMSC proliferation was inhibited after 48, 72, and $96 \mathrm{~h}$ of treatment with $1 \mathrm{mM}$ DMOG $(48 \mathrm{~h}:-26.8 \%$; $72 \mathrm{~h}:-40.2 \%$; and 96 h: $-63.5 \%$; all $P<0.001$ ) and 2 mM DMOG (48 h: $-34.6 \% ;-50.2 \%$; and 96 h: $-69.5 \%$, all $P<0.001$ ), compared with the control group (Fig. 3A).

ALP is a key enzyme mediating osteogenesis. Pre-osteoblasts secrete ALP and promote calcium deposition during bone matrix mineralization [32]. ALP level in the control group was low. Compared with the control group, the DMOG group significantly increased the 


\section{Cellular Physiology Cell Physiol Biochem 2016;39:1391-1403 and Biochemistry \begin{tabular}{l|l} 
DOI: 10.1159/000447843 & (c) 2016 The Author(s). Published by S. Karger AG, Basel
\end{tabular}

Fig. 3. Effects of dimethyloxalylglycine (DMOG) on cell proliferation and alkaline phosphatase (ALP) levels in bone marrow mesenchymal stem cells (BMSCs). (A) BMSCs were treated with different concentrations $(0,0.1,0.5,1$, and $2 \mathrm{mM})$ of DMOG in low-glucose DMEM supplemented with $10 \%$ FBS for $24,48,72$, or $96 \mathrm{~h}$. Cell proliferation was determined by MTT assay. Data are shown as mean \pm standard deviation (SD) of three independent experiments performed in 6 replicates. (B) BMSCs were treated with different concentrations $(0,0.1,0.5,1$, and $2 \mathrm{mM})$ of DMOG in osteogenic medium for 3, 7, 14, and 21 days. ALP levels were determined by colorimetry. Data are shown as mean \pm SD of three independent experiments performed in 5 replicates. ${ }^{* * *} \mathrm{P}<0.001$ vs. 0 mM DMOG; \#\#\#P < 0.001 vs. $0.1 \mathrm{mM}$ DMOG; $\Delta \Delta \Delta \mathrm{P}<0.001$ vs. $0.5 \mathrm{mM}$ DMOG; $\boldsymbol{\Delta} \mathrm{P}<0.05$, $\Delta \mathbf{\Delta} \mathrm{P}<0.01, \boldsymbol{\Delta} \boldsymbol{\Delta} \Delta \mathrm{A}<0.001$ vs. $1 \mathrm{mM}$.

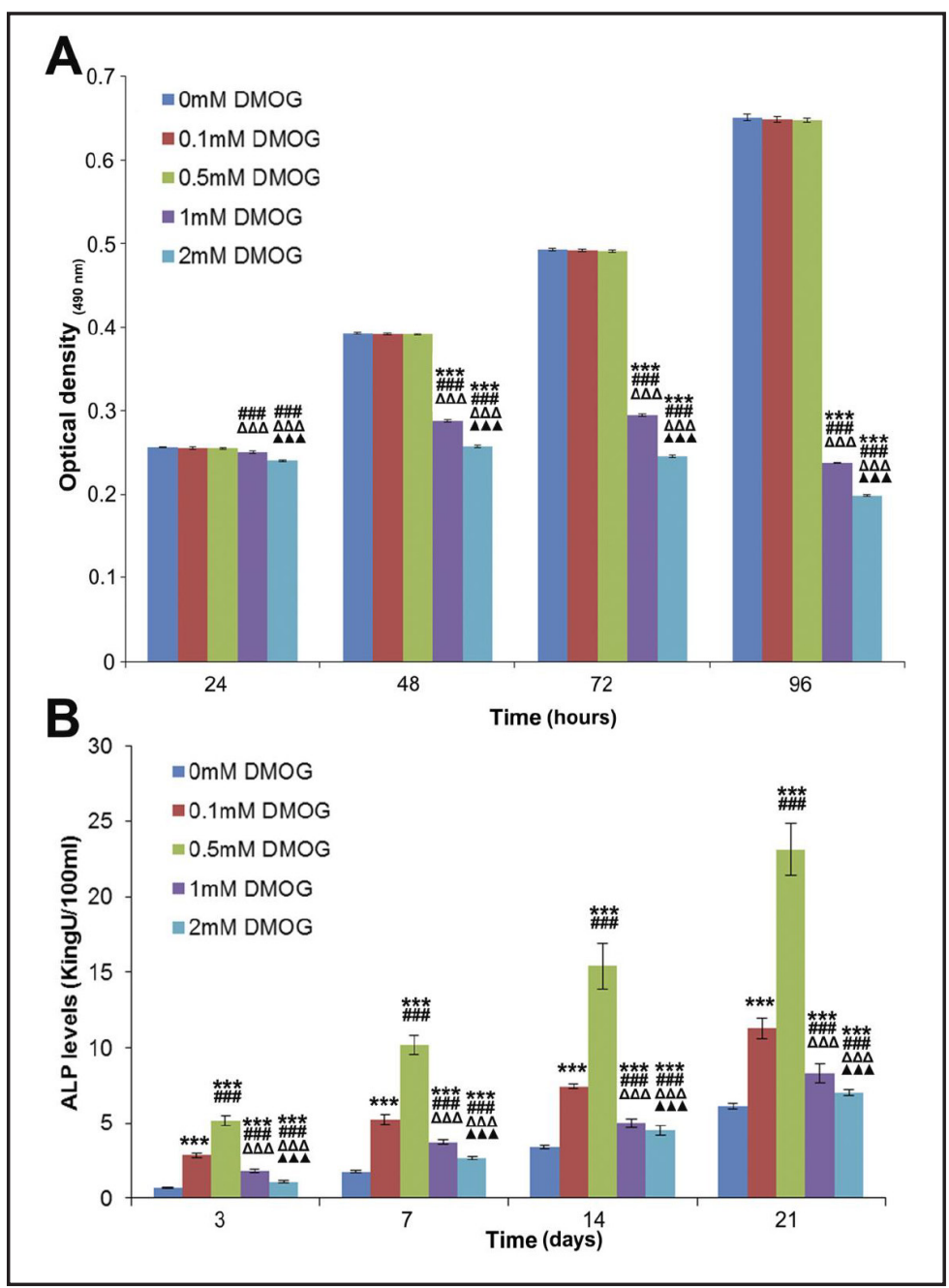

expression of ALP (all $P<0.001$ ), with $0.5 \mathrm{mM}$ DMOG showing the most potent effect at all time points ( 3 days: $+626 \%$; 7 days: $+483 \%$; 14 days: $+352 \%$; and 21 days: $+278 \%$, all $P<$ 0.001) (Fig. 3B). Therefore, $0.5 \mathrm{mM} \mathrm{DMOG}$ was selected for subsequent experiments.

DMOG promoted active-RhoA protein expression and increased ROCK activity, which was inhibited by $Y-27632$

Previous studies showed that RhoA/ROCK signaling played a key role in the regulation of osteogenesis [16-18]. Results showed that after $24 \mathrm{~h}$ of culture, $0.5 \mathrm{mM}$ DMOG increased the expression of GTP-bound RhoA $(P<0.001$ vs. control group). In addition, Y-27632 abolished the DMOG-mediated up-regulation of GTP-bound RhoA protein expressions $(P<$ 0.001 ) (Fig. 4A).

In order to determine the inhibitory effects of Y-27632 on ROCK activity, the ROCK activity assay was performed. Compared with the control group, the DMOG group showed a $315 \%$ increase in ROCK activity ( $\mathrm{P}<0.001)$, which was significantly reduced in the Y-27632 $(-81.9 \%, \mathrm{P}<0.001)$ and DMOG+Y-27632 groups $(-81.1 \%, \mathrm{P}<0.001)$ (Fig. 4B).

DMOG increased ALP levels and calcium deposition during osteogenic differentiation, which were inhibited by $Y-27632$

In order to investigate the effects of DMOG on osteogenic differentiation and matrix mineralization of BMSCs, assays for ALP levels and Alizarin red staining for calcium deposits were used. Compared with the control group, $0.5 \mathrm{mM}$ of DMOG enhanced ALP level after osteogenic induction (all $\mathrm{P}<0.001$ ) (Fig. 5). The addition of Y-27632 reversed the effect of 


\section{Cellular Physiology Cell Physiol Biochem 2016;39:1391-1403

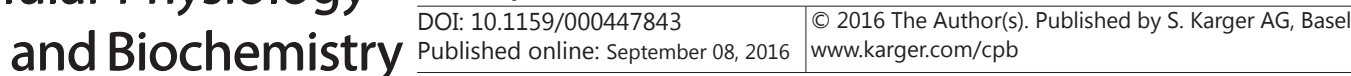 \\ Zhang et al.: Dimethyloxalylglycine Promotes BMSC Osteogenesis}

Fig. 4. Effects of $\mathrm{Y}-27632$ on RhoA, GTP-bound RhoA protein expression and ROCK activity in BMSCs treated with osteogenic medium containing DMOG. BMSCs were treated with osteogenic medium (control), osteogenic media containing $0.5 \mathrm{mM}$ DMOG, $10 \mu \mathrm{M}$ Y-27632, orcontaining $0.5 \mathrm{mM} \mathrm{DMOG}$ and $10 \mu \mathrm{M}$ Y-27632 for 24 h. (A) RhoA, GTPbound RhoA protein expressions were determined by Western blot. GAPDH was used as an inner control. Data are shown as mean \pm SD of three independent experiments performed in triplicate. (B) ROCK activity was determined using a commercial kit. Data are shown as mean \pm SD of three independent experiments performed in triplicate. ${ }^{* *} \mathrm{P}<$ $0.01, * * * \mathrm{P}<0.001$ vs. control; \#\#\#P $<0.001$ vs. DMOG; $\Delta \Delta \Delta \mathrm{P}<$ 0.001 vs. Y-27632.

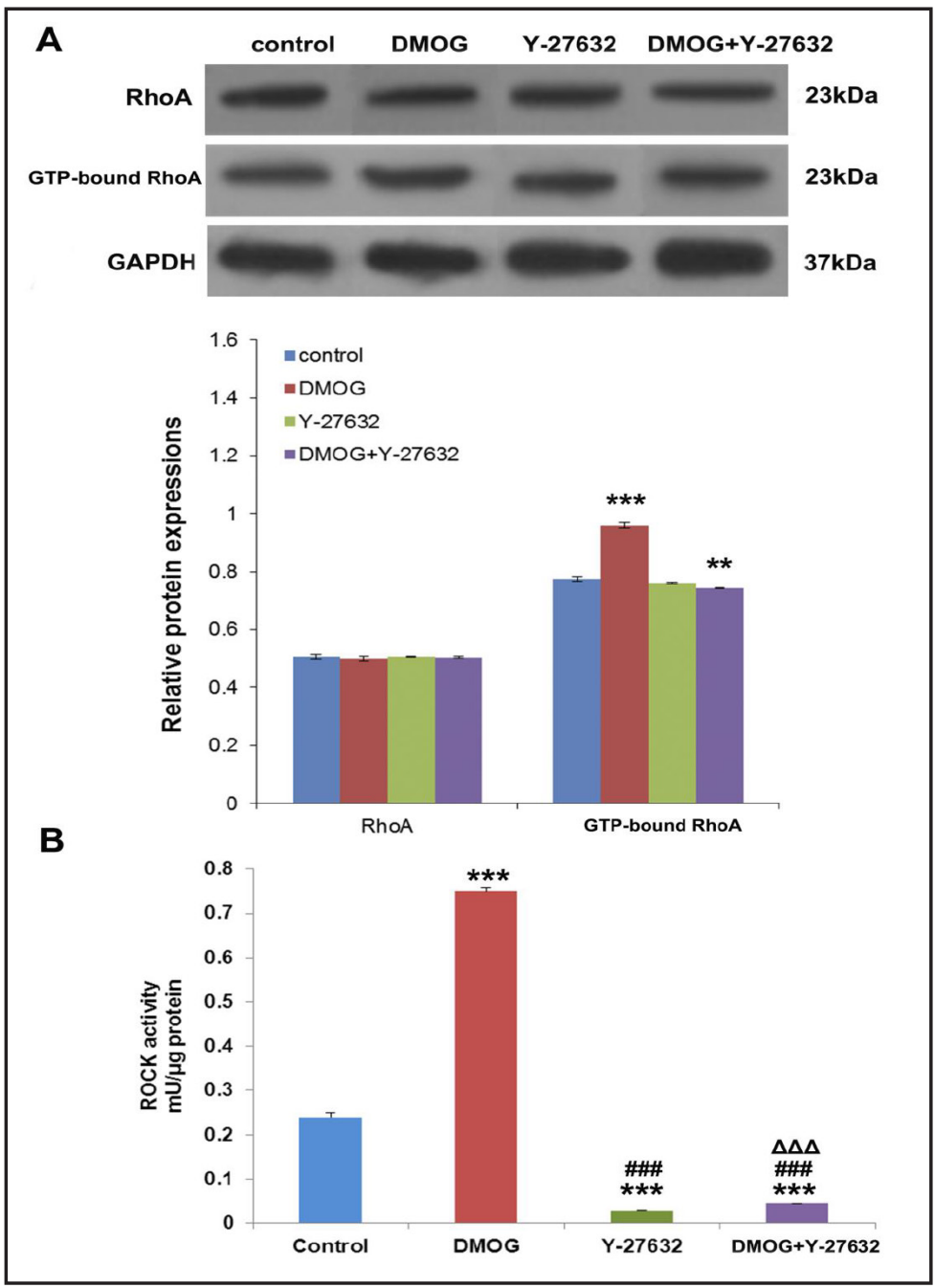

DMOG partially (all P < 0.001) (Fig. 5).

Calcium deposition was enhanced with $0.5 \mathrm{mM}$ DMOG in 21d. However, the addition of Y-27632 partially reversed the calcium deposition induced by DMOG as visualized by alizarin red staining (Fig. 6A). Quantification of calcium secretion on day 21 revealed that $0.5 \mathrm{mM}$ DMOG enhanced calcium deposition after osteogenic induction $(\mathrm{P}<0.001)$ (Fig. 6B). Addition of Y-27632 partially reversed the calcium deposition induced by DMOG $(\mathrm{P}<0.001)$ (Fig. 6B).

DMOG up-regulated RUNX2 and osterix mRNA expression during osteogenic differentiation, which was inhibited by $Y-27632$

The transcription of osteogenic differentiation marker genes was investigated. RUNX2 and OSX are essential transcription factors that control the expression of osteogenic genes. Coinciding with ALP staining and alizarin red staining, $0.5 \mathrm{mM}$ DMOG induced the mRNA levels of RUNX2 (all $P<0.001$ ) and OSX compared with the controls (all $P<0.001$ ) (Fig. 7A and 7B). The addition of Y-27632 partially reversed this increase (all $P<0.01$ ) (Fig. 7A and 7B).

DMOG promoted cytoskeletal alterations and p-cofilin expression during osteogenic differentiation, which were inhibited by $Y-27632$

Actin controls cytoskeletal network and cell morphology. Phalloidin inhibits F-actin depolymerization and upsets the balance between actin polymerization and 
Fig. 5. Effects of Y-27632 on ALP levels in BMSCs treated with osteogenic medium containing DMOG. BMSCs were treated with osteogenic medium (control), osteogenic medium containing $0.5 \mathrm{mM} \mathrm{DMOG}$, osteogenic media containing 10 $\mu \mathrm{M}$ Y-27632, or $0.5 \mathrm{mM}$ DMOG and $10 \mu \mathrm{M}$ Y-27632 for $3,7,14$, and 21 days. ALP levels were determined by colorimetry. Data are shown as mean \pm SD of three independent experiments performed in 5 replicates. ***P $<0.001$ vs. control. \#\#\#P $<0.05$ vs. DMOG; $\Delta \Delta \Delta \mathrm{P}<0.001$ vs. Y-27632.

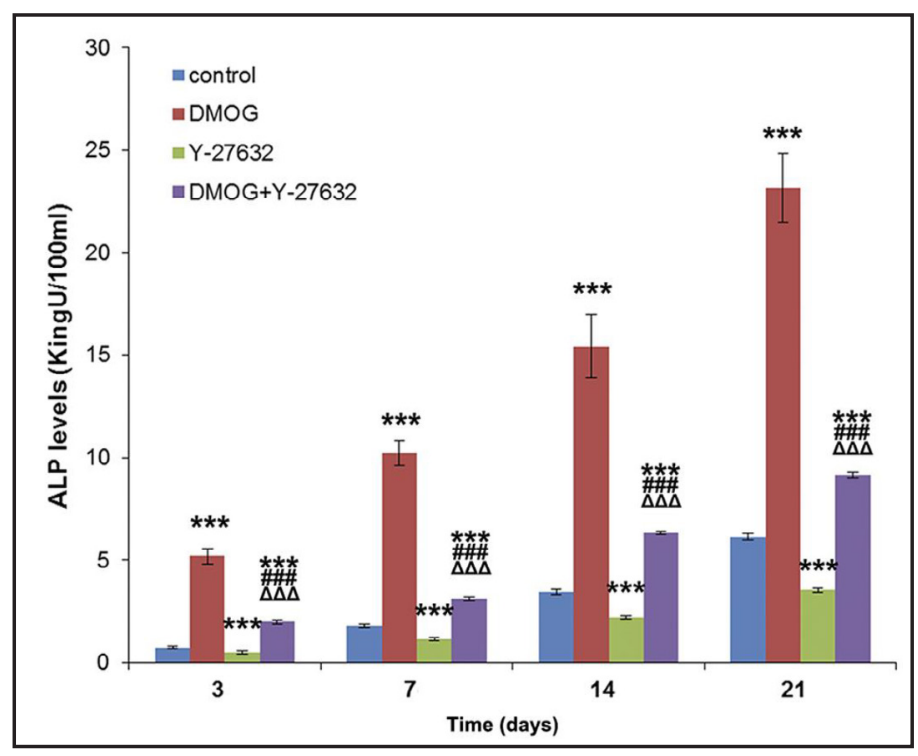

Fig. 6. Effects of Y-27632 on calcium deposition in BMSCs treated with osteogenic medium containing DMOG. BMSCs were treated with osteogenic medium (control), osteogenic media containing $0.5 \mathrm{mM} \mathrm{DMOG}$, $10 \mu \mathrm{M}$ Y-27632, or $0.5 \mathrm{mM}$ DMOG and $10 \mu \mathrm{M}$ Y-27632 for 21 days. (A) Qualitative assay of calcium deposition was evaluated by Alizarin red staining with three independent experiments performed in 3 replicates (magnification: ×200).. (B)Quantitative assay of calcium deposition was determined by colorimetry. Data are shown as mean \pm SD of three independent experiments performed in 3 replicates. ${ }^{* * *} \mathrm{P}<0.001$ vs. control; \#\#\#P $<0.001$ vs. DMOG; $\Delta \Delta \Delta \mathrm{P}<$ 0.001 vs. Y-27632.

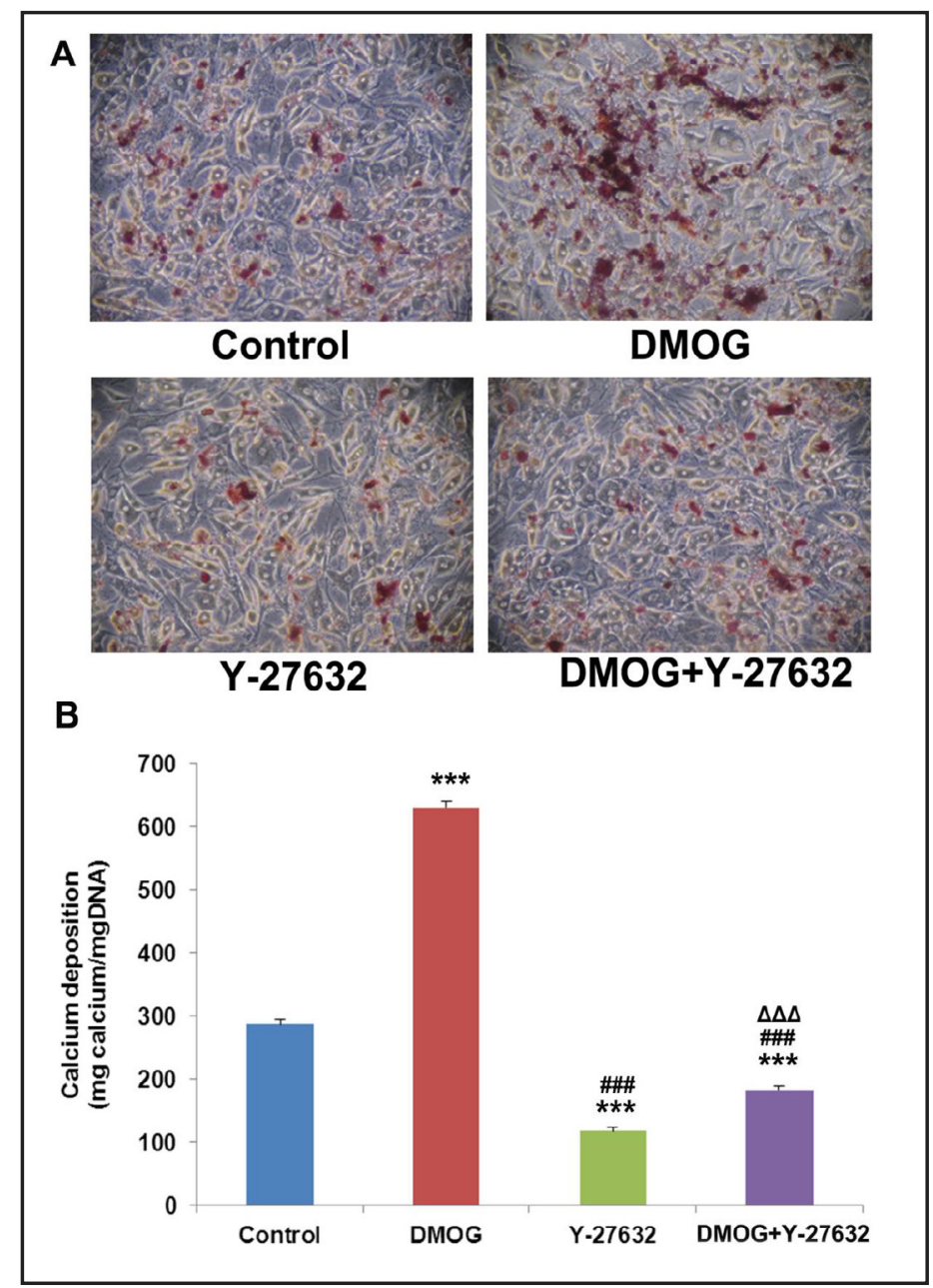

depolymerization. Cofilin mediates actin depolymerization [33, 34]. The effects of $0.5 \mathrm{mM}$ DMOG on BMSC actin cytoskeleton were determined using Western blot of p-cofilin, and FITC-labelled phalloidin staining. Compared with controls, DMOG increased the expression of p-cofilin $(+57 \%, P<0.001)$, while $\mathrm{Y}-27632$ inhibited this increase partially $(P<0.001)$ 


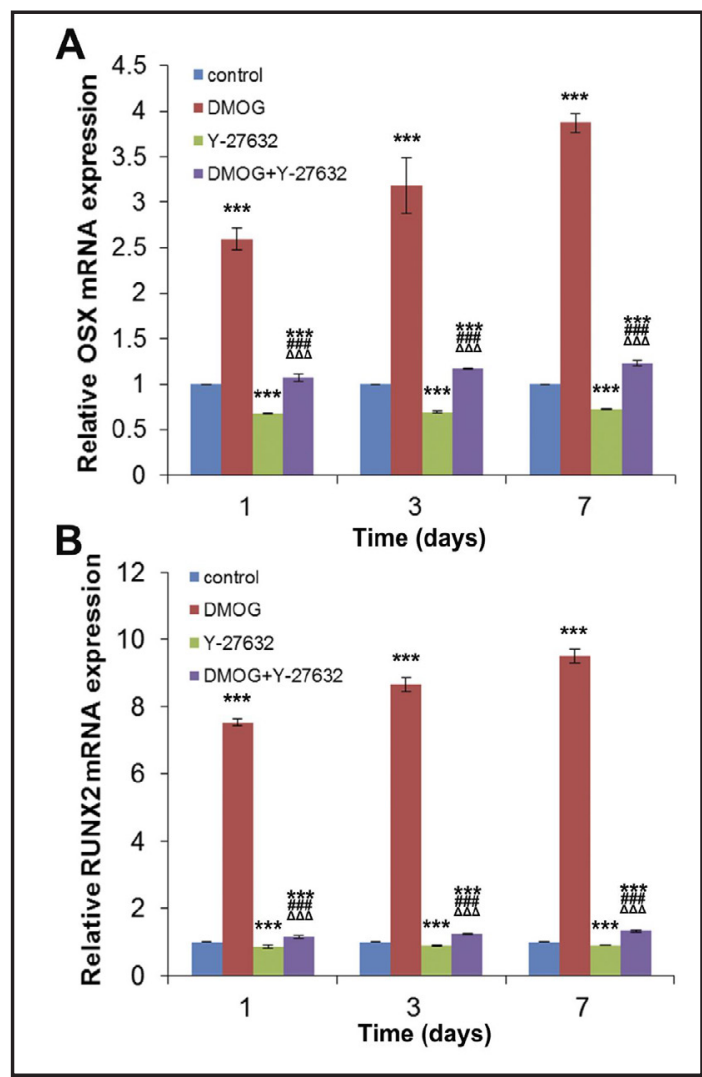

Fig. 7. Effects of Y-27632 on OSX and RUNX2 transcription in BMSCs treated with osteogenic medium containing DMOG. BMSCs were treated with osteogenic medium (control), osteogenic media containing $0.5 \mathrm{mM}$ DMOG, $10 \mu \mathrm{M} \mathrm{Y}-27632$, or $0.5 \mathrm{mM}$ DMOG and $10 \mu \mathrm{M}$ Y-27632 for 1,3 , or 7 days. OSX (A) and RUNX2 (B) mRNA expression was determined by real-time RT-PCR. $\beta$-actin was used as an inner control. Data are shown as mean \pm SD of three independent experiments performed in 6 replicates. ${ }^{* *} \mathrm{P}<0.01,{ }^{* * *} \mathrm{P}<0.001$ vs. control. \#\#\#P $<0.05$ vs. DMOG; $\Delta \Delta \Delta \mathrm{P}<0.001$ vs. Y-27632.

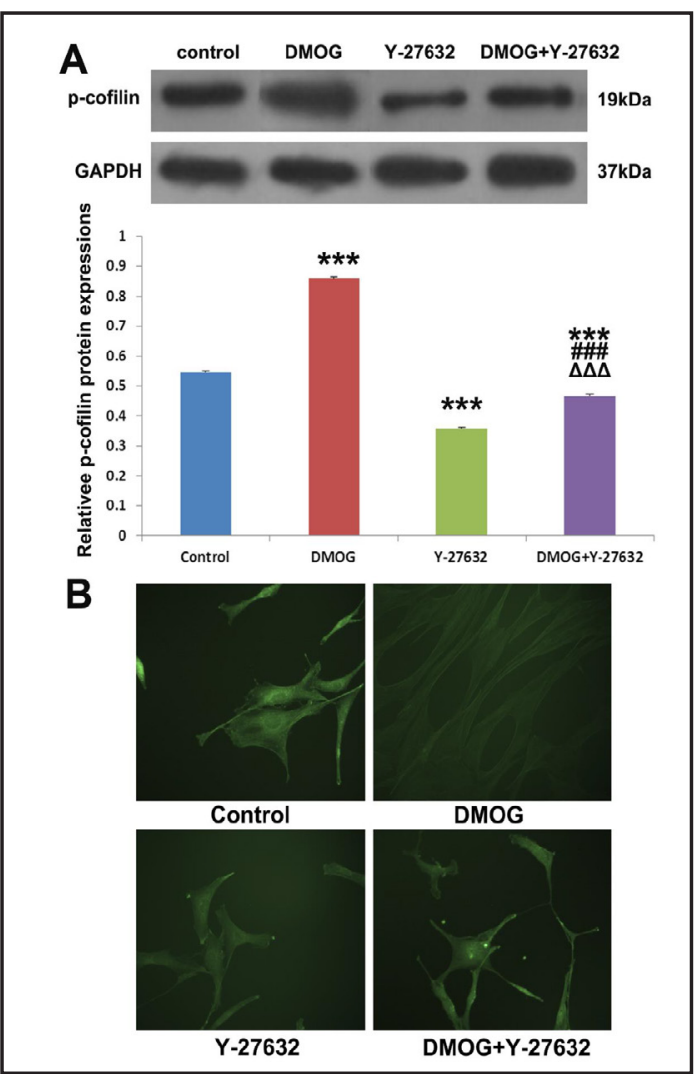

Fig. 8. Effects of Y-27632 on the p-cofilin expression and cytoskeletal morphology in BMSCs treated with DMOG-containing osteogenic medium. BMSCs were treated with osteogenic medium (control), osteogenic media containing $0.5 \mathrm{mM} \mathrm{DMOG}, 10 \mu \mathrm{M}$ Y-27632, or $0.5 \mathrm{mM}$ DMOG and $10 \mu \mathrm{M}$ Y-27632 for 24 h. (A) p-cofilin protein expression was determined by Western blot, using GAPDH as an internal control. Data are shown as mean \pm SD of three independent experiments performed in triplicate. ${ }^{* * *} \mathrm{P}<0.001$ vs. control. \#\#\#P $<0.05$ vs. DMOG; $\Delta \Delta \Delta \mathrm{P}<0.001$ vs. Y-27632. (B) Phalloidin expression was determined by immunofluorescence staining with three independent experiments performed in triplicates (magnification: $\times 400$ ).

(Fig. 8A). Treatment with $0.5 \mathrm{mM} \mathrm{DMOG}$ for $24 \mathrm{~h}$ led to rearrangement of actin filaments compared with controls (Fig. 8B). These changes were abolished, at least in part, by Y-27632 treatment.

\section{Discussion}

DMOG regulates cell differentiation. However, the role of DMOG in osteogenic differentiation of BMSCs is still controversial. Therefore, this study investigated the effect of DMOG on BMSC osteogenesis. DMOG inhibited BMSC proliferation; enhanced ALP levels and calcium deposits after osteogenic induction; promoted the transcription of RUNX2 and OSX; and increased the 


\section{Cellular Physiology Cell Physiol Biochem 2016;39:1391-1403 \\ \begin{tabular}{l|l} 
and Biochemistry Published online: September 08, 2016 & $\begin{array}{l}\text { (c) } 2016 \text { The Author(s). Published by S. Karger AG, Basel } \\
\text { www.karger.com/cpb }\end{array}$
\end{tabular} \\ Zhang et al.: Dimethyloxalylglycine Promotes BMSC Osteogenesis}

expression of p-cofilin. In addition, actin cytoskeleton was rearranged. The results suggested that DMOG promoted BMSC osteogenesis.

In the present study, $0.5 \mathrm{mM} \mathrm{DMOG}$ was the optimal concentration necessary to induce BMSCs osteogenesis. Schultz et al. [35] found that $100 \mu$ M DMOG inhibited the proliferation of vascular smooth muscle cells. Chung et al. [36] found that $125 \mu$ M DMOG inhibited prostate cancer cell proliferation and $1000 \mu \mathrm{M}$ DMOG inhibited prostate cancer cell proliferation. Marchbank et al. [37] found that 10-70 $\mu$ M DMOG promoted HT29 cell proliferation and 70$120 \mu$ M DMOG inhibited HT29 cell proliferation. Indeed, PHI can be divided into two groups: iron chelator and ketoglutaric acid analogues [38]. Previous studies showed that the effects of different PHIs on cell proliferation varied. Similar PHI also showed varying effects on cell proliferation in different studies. In addition, these studies used a number of different cell types. Therefore, additional studies are needed to elucidate the effects of DMOG on the osteogenesis of BMSCs.

The present study showed that DMOG increased osteogenic differentiation of BMSCs. Similarly, Irwin et al. [7]found that $5 \mathrm{mM}$ DMOG inhibited BMSCs osteogenic differentiation and their adipogenic differentiation. Woo et al. [8] showed that DMOG promoted osteogenesis and bone regeneration in vivo. Peng et al. [9] indicated that DMOG prevented bone loss in ovariectomized C57BL/6J mice via enhanced angiogenesis and osteogenesis. Different mechanisms may mediate osteogenic differentiation of cells induced by different PHI, or different concentrations of specific PHI may affect osteogenesis differently. Additional studies are needed to address these issues.

RUNX2 (also named core binding factor- $\alpha 1, \operatorname{Cbf} \alpha 1$ ) is expressed by BMSCs during embryonic development. It plays an important role in BMSCs osteogenic regulation [39]. Previous in vitro studies showed that RUNX2 promoted osteogenesis-related gene expression such as type I collagen, osteopontin, bone sialoprotein, and osteocalcin [40, 41]. RUNX2 activation also mediated BMP9-induced C3H10T1/2 osteogenesis [42]. OSX is an osteogenic-specific transcription factor [43]. The cartilage of OSX-deficient mice developed without bone formation, indicating that endochondral ossification and intra-membranous ossification were inhibited [44]. In OSX-deficient mice, the expression of RUNX2 is normal while the expression of OSX is blocked after RUN2 silencing [43]. The OSX promoter contains the RUNX2-binding domain [45]. However, the genes downstream of OSX are still unclear. Intermittent stretching was found to promote BMSCs OSX mRNA expression, while OSX silencing was found to inhibit BMSCs osteogenesis [46]. In the present study, DMOG promoted the transcription of RUNX2 and OSX.

RhoA belongs to the Ras GTPase super-family. It plays an important regulatory role in cell morphology, actin rearrangement, activation of MAPK signaling, cell cycle, gene transcription, cell migration and adhesion $[21,23,47,48]$. ROCK is the main downstream substrate of Rho. ROCK has two subtypes: ROCK1 and ROCK2 [49, 50]. RhoA-GTPase acts as a molecular switch. RhoA-bound GTP is active [51]. ROCK phosphorylates the cytoskeletal protein regulators, playing an important role in actin cytoskeleton $[21,23]$. In the present study, DMOG promoted BMSC osteogenesis, which was abrogated, at least in part, by Y-27632, a ROCK1 inhibitor, suggesting Rho/ROCK signaling. Other signal transduction pathways may also mediate MSCs osteogenesis. Tang et al. reported that lithium chloride controlled the differentiation of BMSCs directly via Wnt and Hh pathways [52]. Decreased pHi induced by cariporide promoted human umbilical cord-derived mesenchymal stem cells (hUC-MSCs)induced osteogenesis [53]. Silencing of the calcium-binding protein S100A6 expression increased osteogenic differentiation, while S100A6 overexpression inhibited osteogenic differentiation [54].

Novel strategies to promote osteogenesis are important, particularly in diseases associated with an imbalance of osteoblasts and adipocytes in bone marrow like steroidinduced avascular necrosis of the femoral head (SANFH) [55]. DMOG regulates the differentiation of osteoblastic and adipogenic lineage. Its therapeutic role in early-stage SANFH still requires robust clinical evidence. Additional studies are needed to determine whether BMSCs survive transplantation and whether they are the best source of stem cells 


\section{Cellular Physiology Cell Physiol Biochem 2016;39:1391-1403

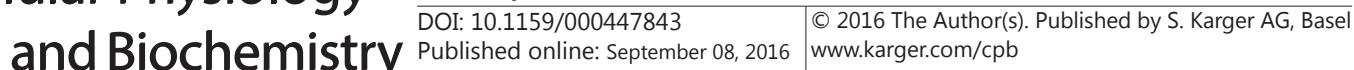 \\ Zhang et al.: Dimethyloxalylglycine Promotes BMSC Osteogenesis}

for bone tissue engineering. Human primary cranial periosteal cells are an appropriate cellular source for bone regeneration [56].

This study is not without limitations. First, only a few proteins and only one signal transduction pathway were examined. Comprehensive studies are needed to explore the effects of DMOG in the osteogenesis of BMSCs. In addition, in vivo studies are needed to provide additional insights into the effects of DMOG. Finally, only osteogenic differentiation was observed and adipogenic differentiation needs to be explored.

In conclusion, DMOG promoted BMSC osteogenic differentiation, which was mediated, at least in part, via activation of RhoA/ROCK, suggesting a potential therapeutic role.

\section{Disclosure Statement}

The authors declare that they have no conflict of interest.

\section{References}

1 Chilov D, Camenisch G, Kvietikova I, Ziegler U, Gassmann M, Wenger RH: Induction and nuclear translocation of hypoxia-inducible factor-1 (HIF-1): heterodimerization with ARNT is not necessary for nuclear accumulation of HIF-1alpha. J Cell Sci 1999;112:1203-1212.

2 James AW, Leucht P, Levi B, Carre AL, Xu Y, Helms JA, Longaker MT: Sonic Hedgehog influences the balance of osteogenesis and adipogenesis in mouse adipose-derived stromal cells. Tissue Eng Part A 2010;16:2605-2616.

3 Velez R, Hernandez-Fernandez A, Caminal M, Vives J, Soldado F, Fernandez A, Pla A, Aguirre M: Treatment of femoral head osteonecrosis with advanced cell therapy in sheep. Arch Orthop Trauma Surg 2012;132:1611-1618.

$4 \quad$ Floyd ZE, Kilroy G, Wu X, Gimble JM: Effects of prolyl hydroxylase inhibitors on adipogenesis and hypoxia inducible factor 1 alpha levels under normoxic conditions. J Cell Biochem 2007;101:1545-1557.

5 Guo W, Yang Z, Xia Q, Liu J, Yu Y, Li J, Zuo Z, Zhang D, Li X, Shi X, Huang C: Arsenite stabilizes HIF-1alpha protein through p85alpha-mediated up-regulation of inducible Hsp70 protein expression. Cell Mol Life Sci 2011;68:475-488.

6 Zhou N, Hu N, Liao JY, Lin LB, Zhao C, Si WK, Yang Z, Yi SX, Fan TX, Bao W, Liang X, Wei X, Chen H, Chen C, Chen Q Lin X, Huang W: HIF-1alpha as a Regulator of BMP2-Induced Chondrogenic Differentiation, Osteogenic Differentiation, and Endochondral Ossification in Stem Cells. Cell Physiol Biochem 2015;36:4460 .

7 Irwin R, LaPres JJ, Kinser S, McCabe LR: Prolyl-hydroxylase inhibition and HIF activation in osteoblasts promotes an adipocytic phenotype. J Cell Biochem 2007;100:762-772.

8 Woo KM, Jung HM, Oh JH, Rahman SU, Kim SM, Baek JH, Ryoo HM: Synergistic effects of dimethyloxalylglycine and butyrate incorporated into alpha-calcium sulfate on bone regeneration. Biomaterials 2015;39:1-14.

9 Peng J, Lai ZG, Fang ZL, Xing S, Hui K, Hao C, Jin Q, Qi Z, Shen WJ, Dong QN, Bing ZH, Fu DL: Dimethyloxalylglycine prevents bone loss in ovariectomized C57BL/6J mice through enhanced angiogenesis and osteogenesis. PLoS One 2014;9:e112744.

10 Amano M, Nakayama M, Kaibuchi K: Rho-kinase/ROCK: A key regulator of the cytoskeleton and cell polarity. Cytoskeleton (Hoboken) 2010;67:545-554.

11 Chu J, Miller CT, Kislitsyna K, Laine GA, Stewart RH, Cox CS, Uray KS: Decreased myosin phosphatase target subunit 1(MYPT1) phosphorylation via attenuated rho kinase and zipper-interacting kinase activities in edematous intestinal smooth muscle. Neurogastroenterol Motil 2012;24:257-266, e109.

12 Jordan SN, Canman JC: Rho GTPases in animal cell cytokinesis: an occupation by the one percent. Cytoskeleton (Hoboken) 2012;69:919-930.

13 Lee JH, Palaia T, Ragolia L: Impaired insulin-stimulated myosin phosphatase Rho-interacting protein signaling in diabetic Goto-Kakizaki vascular smooth muscle cells. Am J Physiol Cell Physiol 2012;302:C1371-1381. 


\section{Cellular Physiology Cell Physiol Biochem 2016;39:1391-1403 \begin{tabular}{l|l|l} 
and Biochemistry & DOI: 10.1159/000447843 & (c) 2016 The Author(s). Published by S. Karger AG, Basel \\
www.karger.com/cpb
\end{tabular} \\ Zhang et al.: Dimethyloxalylglycine Promotes BMSC Osteogenesis}

14 Maddox AS, Azoury J, Dumont J: Polar body cytokinesis. Cytoskeleton (Hoboken) 2012;69:855-868.

15 Ruiz-Loredo AY, Lopez E, Lopez-Colome AM: Thrombin promotes actin stress fiber formation in RPE through Rho/ROCK-mediated MLC phosphorylation. J Cell Physiol 2011;226:414-423.

16 Wang YK, Yu X, Cohen DM, Wozniak MA, Yang MT, Gao L, Eyckmans J, Chen CS: Bone morphogenetic protein-2-induced signaling and osteogenesis is regulated by cell shape, RhoA/ROCK, and cytoskeletal tension. Stem Cells Dev 2012;21:1176-1186.

17 Chen Z, Wang X, Shao Y, Shi D, Chen T, Cui D, Jiang X: Synthetic osteogenic growth peptide promotes differentiation of human bone marrow mesenchymal stem cells to osteoblasts via RhoA/ROCK pathway. Mol Cell Biochem 2011;358:221-227.

18 Xu Y, Wagner DR, Bekerman E, Chiou M, James AW, Carter D, Longaker MT: Connective tissue growth factor in regulation of RhoA mediated cytoskeletal tension associated osteogenesis of mouse adipose-derived stromal cells. PLoS One 2010;5:e11279.

19 Khatiwala CB, Kim PD, Peyton SR, Putnam AJ: ECM compliance regulates osteogenesis by influencing MAPK signaling downstream of RhoA and ROCK. J Bone Miner Res 2009;24:886-898.

20 Zhao YH, Lv X, Liu YL, Zhao Y, Li Q, Chen YJ, Zhang M: Hydrostatic pressure promotes the proliferation and osteogenic/chondrogenic differentiation of mesenchymal stem cells: The roles of RhoA and Rac1. Stem Cell Res 2015;14:283-296.

21 Bernstein BW, Bamburg JR: ADF/cofilin: a functional node in cell biology. Trends Cell Biol 2010;20:187195.

22 Narumiya S, Oceguera-Yanez F, Yasuda S: A new look at Rho GTPases in cell cycle: role in kinetochoremicrotubule attachment. Cell Cycle 2004;3:855-857.

23 Narumiya S, Tanji M, Ishizaki T: Rho signaling, ROCK and mDia1, in transformation, metastasis and invasion. Cancer Metastasis Rev 2009;28:65-76.

24 Sumi T, Matsumoto K, Nakamura T: Specific activation of LIM kinase 2 via phosphorylation of threonine 505 by ROCK, a Rho-dependent protein kinase. J Biol Chem 2001;276:670-676.

25 Van Troys M, Huyck L, Leyman S, Dhaese S, Vandekerkhove J, Ampe C: Ins and outs of ADF/cofilin activity and regulation. Eur J Cell Biol 2008;87:649-667.

26 Vogel S, Wottawa M, Farhat K, Zieseniss A, Schnelle M, Le-Huu S, von Ahlen M, Malz C, Camenisch G, Katschinski DM: Prolyl hydroxylase domain (PHD) 2 affects cell migration and F-actin formation via RhoA/ rho-associated kinase-dependent cofilin phosphorylation. J Biol Chem 2010;285:33756-33763.

27 Campagnoli C, Roberts IA, Kumar S, Bennett PR, Bellantuono I, Fisk NM: Identification of mesenchymal stem/progenitor cells in human first-trimester fetal blood, liver, and bone marrow. Blood 2001;98:23962402.

28 Chung DJ, Hayashi K, Toupadakis CA, Wong A, Yellowley CE: Osteogenic proliferation and differentiation of canine bone marrow and adipose tissue derived mesenchymal stromal cells and the influence of hypoxia. Res Vet Sci 2012;92:66-75.

29 Lee J, Byeon JS, Lee KS, Gu NY, Lee GB, Kim HR, Cho IS, Cha SH: Chondrogenic potential and anti-senescence effect of hypoxia on canine adipose mesenchymal stem cells. Vet Res Commun 2016;40:1-10.

30 Kim KH, Song MJ, Chung J, Park H, Kim JB: Hypoxia inhibits adipocyte differentiation in a HDACindependent manner. Biochem Biophys Res Commun 2005;333:1178-1184.

31 Hutchinson JL, Rajagopal SP, Yuan M, Norman JE: Lipopolysaccharide promotes contraction of uterine myocytes via activation of Rho/ROCK signaling pathways. FASEB J 2014;28:94-105.

32 Muraglia A, Cancedda R, Quarto R: Clonal mesenchymal progenitors from human bone marrow differentiate in vitro according to a hierarchical model. J Cell Sci 2000;113 ( Pt 7):1161-1166.

33 Carlier MF, Pernier J, Montaville P, Shekhar S, Kuhn S: Control of polarized assembly of actin filaments in cell motility. Cell Mol Life Sci 2015;72:3051-3067.

34 De La Cruz EM, Gardel ML: Actin Mechanics and Fragmentation. J Biol Chem 2015;290:17137-17144.

35 Schultz KR, Klarnet JP, Gieni RS, HayGlass KT, Greenberg PD: The role of B cells for in vivo T cell responses to a Friend virus-induced leukemia. Science 1990;249:921-923.

36 Chung LC, Tsui KH, Feng TH, Lee SL, Chang PL, Juang HH: Curcumin provides potential protection against the activation of hypoxia and prolyl 4-hydroxylase inhibitors on prostate-specific antigen expression in human prostate carcinoma cells. Mol Nutr Food Res 2011;55:1666-1676. 


\section{Cellular Physiology Cell Physiol Biochem 2016;39:1391-1403 \begin{tabular}{l|l|l} 
and Biochemistry & DOI: 10.1159/000447843 & (c) 2016 The Author(s). Published by S. Karger AG, Basel \\
www.karger.com/cpb
\end{tabular} \\ Zhang et al.: Dimethyloxalylglycine Promotes BMSC Osteogenesis}

37 Marchbank T, Mahmood A, Harten S, Maxwell PH, Playford RJ: Dimethyloxalyglycine stimulates the early stages of gastrointestinal repair processes through VEGF-dependent mechanisms. Lab Invest 2011;91:1684-1694.

38 Milosevic J, Adler I, Manaenko A, Schwarz SC, Walkinshaw G, Arend M, Flippin LA, Storch A, Schwarz J: Nonhypoxic stabilization of hypoxia-inducible factor alpha (HIF-alpha): relevance in neural progenitor/stem cells. Neurotox Res 2009;15:367-380.

39 Stein GS, Lian JB, van Wijnen AJ, Stein JL, Montecino M, Javed A, Zaidi SK, Young DW, Choi JY, Pockwinse SM: Runx2 control of organization, assembly and activity of the regulatory machinery for skeletal gene expression. Oncogene 2004;23:4315-4329.

40 Javed A, Barnes GL, Jasanya BO, Stein JL, Gerstenfeld L, Lian JB, Stein GS: runt homology domain transcription factors (Runx, Cbfa, and AML) mediate repression of the bone sialoprotein promoter: evidence for promoter context-dependent activity of Cbfa proteins. Mol Cell Biol 2001;21:2891-2905.

41 Pratap J, Javed A, Languino LR, van Wijnen AJ, Stein JL, Stein GS, Lian JB: The Runx2 osteogenic transcription factor regulates matrix metalloproteinase 9 in bone metastatic cancer cells and controls cell invasion. Mol Cell Biol 2005;25:8581-8591.

42 Zhang H, Li L, Dong Q, Wang Y, Feng Q, Ou X, Zhou P, He T, Luo J: Activation of PKA/CREB Signaling is Involved in BMP9-Induced Osteogenic Differentiation of Mesenchymal Stem Cells. Cell Physiol Biochem 2015;37:548-562.

43 Nakashima K, Zhou X, Kunkel G, Zhang Z, Deng JM, Behringer RR, de Crombrugghe B: The novel zinc fingercontaining transcription factor osterix is required for osteoblast differentiation and bone formation. Cell 2002;108:17-29.

44 Zhang C: Transcriptional regulation of bone formation by the osteoblast-specific transcription factor Osx. J Orthop Surg Res 2010;5:37.

45 Nishio Y, Dong Y, Paris M, O'Keefe RJ, Schwarz EM, Drissi H: Runx2-mediated regulation of the zinc finger Osterix/Sp7 gene. Gene 2006;372:62-70.

46 Xiao WL, Zhang DZ, Fan CH, Yu BJ: Intermittent Stretching and Osteogenic Differentiation of Bone Marrow Derived Mesenchymal Stem Cells via the p38MAPK-Osterix Signaling Pathway. Cell Physiol Biochem 2015;36:1015-1025.

47 Etienne-Manneville S, Hall A: Rho GTPases in cell biology. Nature 2002;420:629-635.

48 Vardouli L, Moustakas A, Stournaras C: LIM-kinase 2 and cofilin phosphorylation mediate actin cytoskeleton reorganization induced by transforming growth factor-beta. J Biol Chem 2005;280:1144811457.

49 Chevrier V, Piel M, Collomb N, Saoudi Y, Frank R, Paintrand M, Narumiya S, Bornens M, Job D: The Rhoassociated protein kinase p160ROCK is required for centrosome positioning. J Cell Biol 2002;157:807-817.

50 Riento K, Ridley AJ: Rocks: multifunctional kinases in cell behaviour. Nat Rev Mol Cell Biol 2003;4:446-456.

51 Matozaki T, Nakanishi H, Takai Y: Small G-protein networks: their crosstalk and signal cascades. Cell Signal 2000;12:515-524.

52 Tang L, Chen Y, Pei F, Zhang H: Lithium Chloride Modulates Adipogenesis and Osteogenesis of Human Bone Marrow-Derived Mesenchymal Stem Cells. Cell Physiol Biochem 2015;37:143-152.

53 Gao W, Zhang H, Chang G, Xie Z, Wang H, Ma L, Han Z, Li Q, Pang T: Decreased intracellular pH induced by cariporide differentially contributes to human umbilical cord-derived mesenchymal stem cells differentiation. Cell Physiol Biochem 2014;33:185-194.

54 Li Y, Wagner ER, Yan Z, Wang Z, Luther G, Jiang W, Ye J, Wei Q, Wang J, Zhao L, Lu S, Wang X, Mohammed MK, Tang S, Liu H, Fan J, Zhang F, Zou Y, Song D, Liao J, Haydon RC, Luu HH, He TC: The Calcium-Binding Protein S100A6 Accelerates Human Osteosarcoma Growth by Promoting Cell Proliferation and Inhibiting Osteogenic Differentiation. Cell Physiol Biochem 2015;37:2375-2392.

55 Lee MS, Hsieh PH, Shih CH, Wang CJ: Non-traumatic osteonecrosis of the femoral head - from clinical to bench. Chang Gung Med J 2010;33:351-360.

56 Alexander D, Biller R, Rieger M, Ardjomandi N, Reinert S: Phenotypic characterization of a human immortalized cranial periosteal cell line. Cell Physiol Biochem 2015;35:2244-2254. 